\title{
Descolonizar a participação: pautas para a pedagogia latino-americana
}

\section{Decolonizing participation: an agenda for Latin American Pedagogy}

\author{
Danilo Romeu Streck*
}

\begin{abstract}
RESUMO
$\mathrm{O}$ artigo tem como tema a participação, enquanto meio e fim, na educação para a cidadania. A partir de pesquisas sobre as mediações pedagógicas no orçamento participativo e sobre a pedagogia latino-americana, aponta-se para a necessidade de desconstruir mitos e falácias que se criam em torno da participação, tais como o mito da incapacidade do povo ou da falta de tempo e recursos. Trata-se, como será argumentado, de "descolonizar" a participação, permitindo que ela se torne um efetivo instrumento para a democratização da sociedade. $\mathrm{O}$ conceito de colonialidade serve para ancorar a discussão no âmbito das teorias críticas na América Latina. Como contraponto, são apresentadas pautas que, apesar da diversidade encontrada no subcontinente, pretendem abranger o contexto educacional latino-americano: a participação como um processo político-pedagógico; o conhecimento da história de nossa pedagogia em sua vertente crítica; a compreensão das culturas de participação e suas formas de expressão social e política; a reflexão sobre utopias democraticamente transformadoras.
\end{abstract}

Palavras-chave: Participação. Colonialidade. Cidadania. Pedagogia latino-americana. Mediações pedagógicas.

\footnotetext{
ABSTRACT

The article has participation as its main theme, both as means and as an end for citizenship education. Based on research about pedagogical mediations on participatory budgeting and on Latin American pedagogy, we argue that some myths and fallacies about participation need to be deconstructed,

DOI: $10.1590 / 0104-4060.51760$

* Universidade do Vale do Rio dos Sinos. Programa de Pós-Graduação em Educação. São Leopoldo, Rio Grande do Sul, Brasil. Av. Unisinos, nº 950 - Cristo Rei. CEP: 93022-750. E-mail:
} streckdr@gmail.com 
such as the incapacity of the people, or their lack of time and resources. As outlined in the paper, the challenge is to "decolonize" participation, allowing it to become an effective instrument for the democratization of society. The concept of coloniality serves to anchor this discussion in the broader scope of critical pedagogies. As a counterpoint, we present a series of matters that, in spite of the diversities within the subcontinent, intend to refer to the Latin American educational context as a whole: participation as a political-pedagogical process; knowledge of the history of our pedagogy in its critical roots; understanding of the cultures of participation and the way they express themselves socially and politically; reflection about democratically transforming utopias.

Keywords: Participation. Coloniality. Citizenship. Latin American pedagogy. Pedagogical Mediations.

\section{Introdução}

Nas democracias modernas, a noção de cidadania está estreitamente vinculada à participação. Esta é, de certa forma, um pressuposto para a cidadania e pode encontrar muitas formas de expressão, da clássica participação via voto em eleições periódicas às estratégias de resistência e práticas sociais transformadoras. O objetivo, neste artigo, é identificar entraves para a participação efetiva no contexto latino-americano e, ao mesmo tempo, delinear algumas pautas para a educação, tendo em vista a superação desses entraves e a democratização das sociedades. O pressuposto, como expresso no título, é que também a participação pode se tornar parte de um conjunto de práticas que reforçam o que tem sido identificado como colonialidade.

Trata-se de uma tarefa que requer algumas advertências preliminares. Primeiro, é necessário registrar a diversidade que caracteriza a América Latina também do ponto de vista pedagógico. É, por isso, adequado falar de pedagogias como reconhecimento da pluralidade e diversidade de práticas educativas. Isso representa uma necessária crítica e tentativa de superação de interpretações totalizantes da realidade e das práticas às quais sempre somos seduzidos. No entanto, o reconhecimento da pluralidade pedagógica não nos deve eximir de buscar conexões, distinções e contradições para evitar fragmentações improdutivas e desagregadoras. Paulo Freire refere-se à necessidade de buscar "a unidade na diversidade" como a "grande Utopia" (FREIRE, 1995, p. 36).

Em segundo lugar, a tarefa é dificultada porque nos falta o hábito do diálogo entre as experiências e as reflexões pedagógicas na América Latina. Aprendemos 
pouco das experiências que existem nos diversos lugares deste subcontinente, tanto assim que sempre, quando temos a oportunidade de intercâmbios, nos surpreendemos com a riqueza de práticas imbuídas de intencionalidades transformadoras no sentido de radicalização da democracia. Os processos de sistematização de experiências (JARA HOLLIDAY, 2012) têm revelado, sobretudo, que a aprendizagem da cidadania está acontecendo em uma miríade de lugares. Essas experiências são um lugar privilegiado para buscar novos insights e novas elaborações teóricas.

Ainda precisa ser explicitado que o tema da participação será abordado a partir de uma visão político-pedagógica. Com a expressão "descolonizar a participação" pretende-se indicar que o conceito de participação não é apenas polissêmico, mas também tem sido amplamente usado para manter as relações de dominação. Entende-se a colonialidade na acepção de Aníbal Quijano como "um dos elementos constitutivos e específicos do padrão mundial do poder capitalista" que, por sua vez, "opera em cada um dos planos, meios e dimensões, materiais e subjetivos, da existência quotidiana e da escala social" (QUIJANO, 2009, p. 73).

Pressupondo, como foi dito antes, que a participação é um requisito essencial da cidadania e da democracia, é pertinente a observação de Lynette Schultz (2012) de que estamos diante de um dilema: as elites não têm interesse em verdadeira participação democrática porque esta pode representar sérios riscos para a continuidade de seus privilégios, de seu controle e de seu poder. Já as classes subalternas desconfiam, com uma boa dose de razão, dos discursos de participação uma vez que raramente se sentem de fato representados em seus interesses, visto que os resultados concretos em termos de melhoria das condições de vida são escassos. Entretanto, na expressão de Orlando Fals Borda $(2009$, p. 349), não temos outra opção que não seja a de prosseguir acreditando e investindo no "quixotismo participativo".

A reflexão está dividida em duas partes. Na primeira identifico alguns mitos ou falácias da participação utilizados como formas de perpetuar ou recriar formas de dominação: a falácia da incapacidade do povo, da complexidade dos assuntos, da falta de tempo e escassez de recursos; além das exclusões com base no gênero, na raça e na formação. A ideia de colonialidade como uma matriz de poder que perpassa as relações sociais, das econômicas às geracionais, é apropriada para expressar como esta dominação impregna as formas não democráticas de participação. Como diz Boaventura de Sousa Santos (2007, p. 59), "vivemos em sociedades nas quais não se pode entender a opressão ou a dominação, a desigualdade, sem a ideia de que continuamos sendo, em muitos aspectos, sociedades coloniais". 
Na segunda parte, discutimos os aspectos da participação em propostas pedagógicas identificadas com o campo crítico, buscando delinear algumas pautas para uma perspectiva descolonizadora da participação. Entre elas destaco as seguintes: conceber a participação como um processo político-pedagógico; estudar e contar a história de nossa pedagogia em sua vertente subversiva e rebelde, entendendo e recriando o legado das pedagogias críticas; entender as culturas de participação e suas formas de expressão social e política, desenvolvendo metodologias e estratégias adequadas; por fim, acalentar utopias democraticamente transformadoras através de práticas e teorias descoloniais.

\section{A participação: entre falácias e mitos}

Na própria raiz da palavra "participação", há a referência a "ser parte de ou tomar parte de algo", ou seja, a parte se integra num conjunto mais amplo que não é nem simplesmente o somatório das partes individuais nem a simples adesão a uma das partes que dá a forma e o conteúdo para as demais. O que é, efetivamente, ser parte? Em termos mais elementares, significa a possibilidade de expressar-se junto aos demais; o direito de ser ouvido e, respectivamente, de ouvir os outros; ter condições de acesso aos bens econômicos, sociais e culturais produzidos pela sociedade na qual se vive; exercer o potencial produtivo e criativo como parte inerente ao "ser mais" de que nos fala Paulo Freire (1981); sentir-se responsável pelo destino da comunidade e da sociedade em que se vive. Todas essas características, ou outras que poderiam ser acrescentadas, convergem para o ideal democrático que é assumido pela maioria das sociedades inseridas na civilização moderna como um padrão desejável de organização social.

A essa visão de participação democrática contrapõe-se uma prática de participação que, sob nomes diferentes, esconde realidades com grandes semelhanças. De um lado temos a participação - abertamente forçada ou induzida - em regimes totalitários e populistas. Carole Pateman chama a atenção de que, em muitos casos, por exemplo, após o colapso da República de Weimar na Alemanha, a participação passou a ser muito mais associada com o totalitarismo do que com a democracia. A partir da popularidade do conceito nas últimas décadas e os usos controvertidos da participação, ela lança uma pergunta provocadora: “(...) a recente intensificação dos movimentos em prol de uma participação maior coloca uma questão crucial para a teoria política: qual o lugar da 'participação' numa teoria da democracia moderna e viável?’ (PATEMAN, 1992, p. 9). É uma pergunta que ecoa para todas as ciências e todos os cidadãos. 
Outro questionamento nos vem da realidade do atual mundo globalizado no qual as políticas neoliberais se tornaram hegemônicas. Sabe-se que o "sujeito neoliberal" ali produzido (MCCARTHY; PITTON; KIM; MONJE, 2011) é responsável pela sua própria sobrevivência e com isso a dimensão do social assume um aspecto secundário. É como se ele pudesse prescindir da sociedade para realizar os seus objetivos profissionais e, sobretudo, de consumo. A participação tende a estar restrita a contextos menores, que inclusive pode ser incentivada, por exemplo, como fator de harmonia no local de trabalho ou de resolução de problemas mais imediatos. Nas palavras dos autores citados, "o sujeito neoliberal é um sujeito que opta por ele mesmo entre diferentes alternativas sociais, políticas e econômicas, e não um sujeito que luta em conjunto com os outros para transformá-las ou organizá-las" (MCCARTHY; PITTON; KIM; MONJE, 2011, p. 54).

Dessas observações surge a necessidade, hoje, de qualificar a participação. Neste texto optamos por qualificar a participação com o adjetivo "democrática" (FRICKE, 2013). Outras adjetivações expressam nuances dessa participação democrática, como "participação cidadã", "participação popular" ou "participação crítica". O quixotismo participativo do qual falamos na introdução refere-se a este tipo de participação. As observações também revelam que a linha divisória entre participação e manipulação, participação e controle, participação e cooptação, geralmente, é muito tênue e que, no mundo real das relações sociais, a participação democrática se coloca como um processo sob permanente vigilância e autocrítica.

Há vários mitos ou falácias que corroboram a prática de uma participação limitada, manipulada ou cooptada. Uma delas é que as pessoas "comuns" são incapazes de compreender os problemas. Essa percepção é retransmitida em todos os níveis e esferas da vida, do micro ao macro. Já na família a criança é "protegida" do envolvimento com os problemas e as dificuldades enfrentadas pelos pais, os irmãos ou os avós. Na escola a preocupação está cada vez mais centrada em produzir resultados para dar conta de conteúdos que fazem parte de avaliações nacionais e internacionais. Em nível macro, as decisões são restritas aos especialistas - técnicos ou políticos - que supostamente entendem os problemas e estão capacitados a proporcionar as respostas.

Não há dúvida de que, num mundo interconectado, os problemas alcançam uma maior complexidade e de que bons técnicos, especialistas e pesquisadores são necessários. Isso, no entanto, não exclui integrar outras "partes" na busca de compreensão do problema e de soluções. Temos exemplos da pesquisa com o orçamento participativo no Sul do Brasil que ilustram bem a compreensão de problemas em sua dimensão estrutural por pessoas das comunidades locais. Quando um morador de uma vila ribeirinha reclamava das constantes enchen- 
tes que atingiam suas modestas casas, um agricultor que vive mais próximo à nascente do rio chamava a atenção para o tratamento do controle das águas que passava também - e quem sabe sobretudo - pelos cuidados com as margens do rio ao longo de seu percurso. Outro agricultor dizia que a comunidade havia elaborado um "produto" para controlar uma doença de determinada planta, mas esperava que as pesquisas científicas em laboratórios contribuíssem para tornar este antídoto mais eficiente. Um olhar simplesmente técnico, no primeiro caso, provavelmente não teria feito as conexões construídas no diálogo entre cidadãos "comuns" e, no segundo caso, os técnicos não teriam acesso a um conhecimento de experiência que pode trazer uma grande contribuição para as suas pesquisas.

Essas práticas não se restringem ao mundo adulto. Há experiências, com orçamento participativo com crianças (OP Criança), que mostram como integrar as crianças, na compreensão da realidade da escola e da comunidade, traz benefícios não apenas para elas, mas também para o conjunto da comunidade. César Muñoz, que assessorou o OP Criança na cidade de São Paulo, faz uma afirmação que soa a senso comum, mas está muito distante de sê-lo como prática: “(...) não existe democracia se esta não for intergeneracional. A meu ver, não existe OP democrático se não incorpora todas as idades em sua organização" (MUÑOZ, 2004, p. 92). Para que essa participação se efetive, são necessárias metodologias adequadas às idades, como aquela desenvolvida por Munõz para a participação das crianças e que ele caracteriza com as preposições desde/ com, ou seja, desde o mundo da criança e com ela. Ao adulto caberia o papel de uma presença suave, "nem tão próxima da infância, da adolescência e da juventude que as invada, ou anule, nem tão longe que crie nelas o sentimento de abandono" (MUÑOZ, 2004, p. 67).

Outra falácia diz respeito ao tempo e aos recursos. É bem verdade que a participação requer tempo, um bem cada vez mais precioso numa sociedade competitiva, com insegurança quanto ao futuro, em termos de emprego, e com maior oferta de consumo. Isso, no entanto, não pode servir de desculpa para não abrir espaços e possibilidades de participação. Criadas as condições, as pessoas encontram tempo e estão dispostas a investir seus recursos para participar. Podem ser poucas em relação à população geral, mas sua disponibilidade deve ser entendida como sinal de resistência à tendência desagregadora dominante. Ao perguntar sobre aspectos positivos do orçamento participativo, obtivemos respostas como as que seguem: "A população começa a se articular"; "Algumas das necessidades das comunidades são contempladas"; "Informa e empodera a população"; "Diferentes visões e opiniões para a formalização de ideias"; "Mais conhecimento da região"; "Possibilidade de discussão"; "Podemos nortear os projetos". 
Mesmo em uma proposta de participação popular com grandes limitações devido a questões políticas (partidos e atores com diferentes visões e concepções) e estratégicas (ampla área geográfica e diversidade demográfica) ${ }^{1}$, um grande número de pessoas se mobiliza para participar de audiências e reuniões, às vezes viajando dezenas ou centenas de quilômetros e gastando seu dinheiro para custear as despesas. Os motivos são diversos, desde conhecer melhor a sua região ou a própria máquina do Estado até a possibilidade de influenciar alguma decisão quanto à alocação de recursos públicos.

Descolonizar a participação significa estar atento para as condições objetivas e subjetivas que prendem a participação aos padrões de dominação. Assim é justo perguntar por que há menos mulheres participando, especialmente em níveis mais altos de representação, mesmo dentro de um espaço que se entende como vanguarda em termos de participação popular; por que há tão poucos negros quando eles compõem significativa parcela da população; ou por que jovens e idosos se fazem pouco presentes nas reuniões. Ao mesmo tempo, descolonizar significa debruçar-se sobre a criação de estratégias que promovam a superação dessas condições de dominação e exclusão. A seguir propomos algumas pautas a partir de uma preocupação pedagógica de formação para a participação.

\section{Pautas para a pedagogia latino-americana}

Neste espaço apresentamos de forma resumida alguns tópicos que de certa forma fazem parte da tradição educativa latino-americana, mas que devem ser revisitados em cada contexto social e histórico. Valho-me principalmente da experiência da educação popular, que tem em Paulo Freire uma de suas referências básicas. Também considerado internacionalmente um dos grandes expoentes, quando não criador, da pedagogia crítica. Esta, sem grande rigor, busca "expor o modo como as relações de poder e desigualdade (social, cultural, econômica) em sua miríade de combinações de formas e complexidades, manifestam-se e são postas em questão na educação formal e não formal" (APPLE; AU; GANDIN, 2011, p. 14). Ou seja, temos uma produção pedagógica que nos permite avançar, evitando o desperdício das experiências e alargando e aprofundando as reflexões.

1 Os dados foram obtidos em assembleias e audiências do orçamento participativo/consulta popular no estado do Rio Grande do Sul (Brasil) entre os anos de 2011 e 2014. 


\section{Participação como prática pedagógica}

Participação se aprende participando. Essa afirmação contém uma obviedade que talvez tenha o efeito de tornar a participação invisível do ponto de vista pedagógico. No entanto, se analisamos os espaços de educação escolar e não escolar nos quais se ensaia e pratica a participação como um exercício pedagogicamente refletido, veremos que os mesmos são relativamente escassos. Limito-me a dois desses espaços, respectivamente, a escola e as já referidas experiências do orçamento participativo.

A dificuldade de fazer da participação uma prática da comunidade escolar foi bem descrita por Paulo Freire em sua experiência como secretário de educação da cidade de São Paulo. Ele relata seu esforço de "democratizar o poder", reconhecendo a voz de todos os sujeitos que compõem a comunidade escolar: direção, corpo docente, funcionários, pais e, não por último, os próprios alunos. Freire relata como as estruturas pesadas, de tradição autoritária, são um obstáculo para a participação para a participação. "A democracia, diz ele, demanda estruturas democratizantes e não estruturas inibidoras da presença participativa da sociedade civil no comando da res-pública" (FREIRE, 1995, p. 75). Menciona também a resistência de diretoras, coordenadoras pedagógicas e professores que "hospedavam" neles a herança colonial, autoritária e elitista. "Que isso? Indagavam às vezes, entre surpresas e feridas, será que vamos ter que aturar palpites e críticas dessa gente ignorante que nada sabe de Pedagogia?" (FREIRE, 1995, p. 76).

Não importa aqui avaliar o sucesso da experiência relatada por Paulo Freire, mas a intencionalidade de tornar a escola um lugar de aprendizagem da participação democrática. Se olharmos para nossa formação, possivelmente haverá experiências marcantes tanto positivas quanto negativas de participação. Um simples clube de leitura, com diretoria eleita pelos colegas, com reuniões de prestação de contas e discussão de projetos pode fazer a diferença. Cabe à professora exercer o seu papel de "presença suave" já referida anteriormente. O que se pretende destacar é que, independente das condições adversas - ou até por causas delas -, é possível desenvolver processos participativos.

A outra experiência, em nível macro, é o orçamento participativo. De modo geral, nele são discutidas demandas das comunidades e definidas prioridades que eventualmente se tornam parte do orçamento público. Existe hoje um grande número de orçamentos participativos em todo o mundo com uma variedade de formatos e níveis de participação. O que convém ressaltar, no entanto, é o seu potencial formativo em termos de cidadania. Íria Charão (2005), uma das figuras-chave do processo pioneiro em Porto Alegre (1989-1992) e depois no estado do Rio Grande do Sul (1999-2002), destaca este papel central de "despertar cidadãos" no orçamento participativo: 
Procuro ter um olhar diferente sobre a participação e procuro passar isto para as pessoas, porque eu acho que nós não podemos nos propor a ser uma equipe de arrecadar demandas. Para isso a comunidade sabe se organizar e o faz com os mecanismos que sempre usou. Agora o que é importante neste processo é de fato despertar cidadãos. Nisso já se percebem todas as dificuldades que têm com essa nova visão na qual se mudam conceitos na relação do cidadão com o estado. Eu acho que uma das coisas que nós podemos eliminar com um processo desses é o paternalismo e o assistencialismo, porque a gente vai ter cidadania plena quando se colocam questões e se discutem (CHARÃO, 2005, p. 186).

São poucos os gestores públicos que têm a preocupação de despertar cidadãos. Para a maioria, o estado de sonolência é bem mais conveniente, mesmo que haja alguns espasmos de participação que apenas atestam a dificuldade de ser ouvido pela ausência de mecanismos estruturais adequados ou pelo distanciamento das instâncias representativas.

\section{Refazer a memória da educação crítica e emancipadora}

Temos na América Latina uma rica experiência pedagógica que é praticamente desconhecida. São poucos os educadores e pensadores da educação, anteriores a Paulo Freire, conhecidos e estudados em nossos cursos de licenciatura e também nos cursos de pós-graduação. O resultado disso é que temos uma reduzida memória pedagógica.

Nessa memória podem ser integradas pelo menos quatro vertentes. A primeira delas compreende os povos originários cujas práticas ainda continuam vivas. No Brasil, por exemplo, pouco conhecemos dos povos guarani. O padre Bartomeu Meliá (2010), estudioso dos povos guarani, salienta que aos olhos do visitante, ou mesmo do estudioso, passa despercebido o fato de que existe uma formalidade, mesmo que não haja escolas como nós as conhecemos. O indivíduo se educa na vida comunitária que representa a palavra-alma que, por sua vez, se manifesta nas reuniões comunitárias e sobretudo nos rituais.

A outra vertente é a dos negros trazidos para estas terras como escravos. Enaltecemos o papel do negro nas expressões culturais como música e dança, mas pouco falamos de sua contribuição para a educação. São saberes de resistência nas lavouras e nas senzalas; são experiências de organização nos quilombos; são memórias de uma ancestralidade que se recriou em novas formas de existência. Abdias de Nascimento, intelectual e líder do movimento negro no Brasil, reclama do suposto universalismo das ciências modernas, no qual podemos incluir a pedagogia: 
Como poderíamos chamar as ciências humanas, históricas - etnologia, economia, história, antropologia, sociologia, psicologia e outras - nascidas, cultivadas e definidas para povos e contextos socioeconômicos diferentes, prestar útil e eficaz colaboração ao conhecimento do negro, sua realidade existencial, seus problemas e aspirações e projetos? Seria a ciência social elaborada na Europa ou nos Estados Unidos tão universal em sua aplicação? Os povos negros conhecem na própria carne a falaciosidade do universalismo e da isenção dessa "ciência". (NASCIMENTO, 2002, p. 271).

A terceira vertente seria a dos críticos da colônia, na qual encontramos figuras como Bartolomeu de las Casas e Guaman Poma de Ayala. Mas havia também mulheres pouco lembradas. Trazemos, por isso, à lembrança Sor Juana Inés de la Cruz (1651-1695), que desafiou a sociedade patriarcal de sua época ao estudar e discutir em pé de igualdade com os intelectuais. Fazia-o com grande astúcia, como quando diz para seus interlocutores: "Yo no estudio para escribir, ni menos para enseñar, que fuera en mí desmedida soberbia, sino sólo por ver si con estudiar ignoro menos" (CRUZ, 2001, p. 32). Diz que, devido à grande inclinação para as letras, chegou a pedir a Deus que apagasse a luz de seu entendimento, uma vez que, segundo alguns, este era desnecessário ou inclusive prejudicial. No entanto, em seguida apresenta um rol de mulheres bíblicas com virtudes que dificilmente poderiam ser negadas pelas autoridades eclesiásticas: Débora, ditando leis e governando o povo; Abigail com seus dons proféticos; Éster com sua capacidade de persuasão; Ana com sua perseverança; entre outras.

Por fim, temos a vertente do pensamento de emancipação e de constituição das novas repúblicas latino-americanas, na qual encontramos figuras expressivas como José Martí, em Cuba, Domingo Faustino Sarmiento, na Argentina, e José Pedro Varela, no Uruguai. Dentre todos eles, no entanto, destaco o mestre de Simón Bolívar, Simón Rodríguez. Ele compreendeu em profundidade o pecado original do ser colônia:

El mal de la América es inveterado. Tres siglos de ignorancia y de abandono en el Pueblo, y de indiferencia en el Gobierno, dan mucho qué hacer hoy, a los que emprenden instruir, animar e poner en actividad. De todos los obstáculos que tienen qué remover, la APATIA es el mayor.

Los Pueblos no han sido Monárquicos, sino Colonos, es decir, que jamás pensaron en Gobiernos, sino en mantenerse y obedecer. (RODRÍGUEZ, 2006, p. 185). 
Outras vertentes posteriores poderiam ser adicionadas, como as experiências de educação anarquista, a formação de trabalhadores nos sindicatos, a preocupação pedagógica com a justiça social por parte de setores progressistas das igrejas, a educação de adultos como aquela na qual se originou a prática alfabetizadora de Paulo Freire. Todas essas experiências contribuíram para compor o quadro de pedagogias críticas ou emancipatórias que temos hoje na América Latina.

\section{Conhecer as culturas de participação}

Já aludimos ao fato de que participação pode ter significados muito diferentes para pessoas e grupos. Referimo-nos a essas diferenças com o conceito de culturas de participação. Na já referida entrevista, Íria Charão (2005), coordenadora do orçamento participativo estadual no Rio Grande do Sul (1999-2002), destacou diferentes formas e compreensões de participação como um grande desafio. Por exemplo, no Brasil o termo cacique tem uma conotação negativa e é referido às lideranças autoritárias. Entre os povos indígenas, no entanto, o cacique é uma autoridade legítima dentro de uma outra visão de participação.

Trazemos dois exemplos, um deles de uma comunidade do interior do Brasil e outro de um movimento internacional inspirado nas mídias sociais. Cênio Back Weyh, em sua tese de doutorado, estudou uma comunidade tradicional, em que as pessoas se encontravam para discutir suas necessidades e formular propostas para o orçamento estadual. Na realidade, essa comunidade já havia construído uma rede de participação formada por comunidades eclesiais, sociedades recreativas, times de futebol, entre outros, para assegurar as condições de vida. O que a iniciativa governamental fez com o orçamento participativo foi mobilizar essa força já existente, como se vê no seguinte depoimento:

A maioria dos nossos políticos, eles gostam de governar para onde tem líderes fortes e reivindicações de pessoas mais fortes também representativas. As grandes distâncias que nos separam da nossa capital, as pequenas comunidades, os municípios geralmente eram esquecidos (...). E assim, o OP exatamente fez despertar em todas as comunidades, pequenas ou grandes, e conseguiu reivindicar mais uniformemente os pleitos e distribuir este dinheiro (apud WEYH, 2011, p. 173). 
No caso, o orçamento participativo proporcionou significativos ganhos econômicos através da criação de pequenas agroindústrias que alavancaram cultivos tradicionais na região, como a mandioca e a cana-de-açúcar. Estabeleceu-se um processo de confiança mútua entre governo e comunidade, condição fundamental para o sucesso do orçamento participativo. O governo respeitou as formas de organização local e, ao mesmo tempo, ampliou o campo de visão das comunidades locais ao conectá-las com outras realidades locais e regionais. Além disso, o povo da localidade sentiu que sua voz foi ouvida e sua mobilização teve resultados concretos.

Olhemos uma cultura de participação muito diferente que está em processo de formação, especialmente entre os jovens. Um estudo da "revolução egípcia" de 2011 (MALONE, 2012), com a ocupação da Praça Tahrir, mostra o papel decisivo das mídias sociais para convocar especialmente os jovens para participar dos protestos. As mídias sociais, como facebook e twitter, fizeram o papel de "tecnologias disruptivas" dentro de uma sociedade em que o acesso aos meios de comunicação convencional era restrito à visão oficial, havendo uma desconfiança geral sobre as notícias ali veiculadas. No entanto, o autor também ressalva que a internet é um espaço de múltiplos conflitos, envolvendo muito autores, das grandes corporações aos coletivos de hackers.

Essa constatação é comprovada por Matthew Hindman no livro The myth of digital democracy (2009), no qual o autor mostra a distância que existe, na internet, entre "dizer", ou postar uma mensagem, e ser ouvido. "While it is true that citizens face few formal barriers to posting their views online, this is openness in the most trivial sense." (HAIDMAN, 2009, p. 18). A internet, segundo ele, criou novas hierarquias que - como as antigas - não são neutras. De novo, entre falácias e possibilidades (CASTELLS, 2013), é necessário entender as culturas de participação, antigas e novas.

\section{Como conclusão}

As reflexões, apresentadas neste texto, trouxeram mais perguntas do que respostas. Talvez não pudesse ser diferente. Afinal, como lembra Boaventura de Sousa Santos (2007, p. 19), "nossas grandes teorias das ciências sociais foram produzidas em três ou quatro países do Norte. Então, nosso primeiro problema para quem vive no Sul é que as teorias estão fora do lugar; não se ajustam realmente a nossas realidades sociais". Esse desafio vale também para a participação e tem implicações para a educação. Em que reside, afinal, este desafio? 
A questão pedagógica central parece ser a de cultivar a capacidade de olhar para o mundo em que se vive com um realismo esperançoso. Por isso Walter Mignolo (2010) fala da necessidade de um pensamento fronteiriço ou de epistemologias fronteiriças, a partir do reconhecimento de que o pensamento ocidental moderno é, de certa forma, inevitável e, ao mesmo tempo, limitado e enganoso. O pensamento fronteiriço, respectivamente as pedagogias fronteiriças, implica a consciência de que existem outros lugares a partir de onde ler o mundo, criando o que ele chama de "gramática de descolonialidade".

Essa gramática será desenvolvida a partir de práticas existentes ou que se recriam. Tem razão Boaventura de Sousa Santos (2007, p. 111) quando, ao analisar os movimentos sociais, afirma: "Não posso avançar mais do que a prática mais avançada". Os exemplos referidos neste texto podem servir como estímulo para debruçar-nos sobre as práticas participativas em políticas públicas, em movimentos sociais, em salas de aula e em instituições para identificar, sistematizar e analisar elementos de uma gramática descolonial da participação.

\section{REFERÊNCIAS}

APPLE, M. W.; AU, W.; GANDIN, L. A. (Eds.). Educação crítica: análise internacional. Porto Alegre: Artmed, 2011.

CASTELLS, M. Redes de indignação e esperança: movimentos sociais na era da internet. Rio de Janeiro: Zahar, 2013.

CHARÃO, Í. Despertar cidadãos. Diálogo com Íria Charão. In: STRECK, D. R.; EGGERT, E.; SOBOTTKA, E. A. Dizer a sua palavra: educação cidadã, pesquisa participante e orçamento público. Pelotas: Seiva, 2005.

CRUZ, S. J. I. Respuesta a Sor Filotea (Carta Atenagórica). 3. ed. México D.F.: Mexicanos Unidos, 2001.

FALS BORDA, O. Una sociologia sentipensante para América Latina: Antología. Bogotá: Siglo del Hombre, 2009.

FREIRE, P. Pedagogia do oprimido. 9. ed. Rio de Janeiro: Paz e Terra, 1981.

FREIRE, P. Política e educação. 2. ed. São Paulo: Cortez, 1995.

FRICKE, W. A realistic View of the Participatory Utopia. Reflections on Participation. International Journal of Action Research, v. 9, n. 2168-2191, 2013.

HINDMAN, M. The myth of digital democracy. Princeton: Princeton University Press, 2009. 
JARA HOLLIDAY, O. La sistematización de experiencias: práctica y teoría para otros mundos posibles. San José, C.R.: Alforja, 2012.

MALONE, M. Tweeting history: an inquiry into aspects of social media in the Egyptian revolution. In: HALL, B. L.; CLOVER, D.; CROWTER, J.; SCANDRETT, E. (eds). Learning and education for a better world: the role of social movements. Rotterdam: Sense, 2012. p. 169-182.

MCCARTHY, C.; PITTON, V.; KIM, S.; MONJE, D. Movimento e estase na reorientação neoliberal da escolarização. In: APPLE, M.; AU, W.; GANDIN, L. A. Educação crítica: análise internacional. Porto Alegre: Artmed, 2011. p. 49-65.

MELIÁ, S. J. B. Educação guarani segundo os Guarani. In: STRECK, D. R. (Org.). Fontes da pedagogia latino-americana: uma antologia. Belo Horizonte: Autêntica, 2010. p. 37-54.

MIGNOLO, W. Desobediencia epistémica: retórica de la modernidad, lógica de la colonialidad, gramática de la descolonialidad. Buenos Aires: Del Signo, 2010.

MUÑOZ, C. Pedagogia da vida cotidiana e participação cidadã. São Paulo: Cortez, 2004.

NASCIMENTO, A. do. O Quilombismo (Panamá, 1980). In: NASCIMENTO, A. do. Quilombismo: documento de uma militância pan-africanista. 2. ed. Brasília/Rio de Janeiro: Fundação Palmares /OR Editor Produtor, 2002. p. 26-30.

PATEMAN, C. Participação e teoria democrática. Rio de Janeiro: Paz e Terra, 1992.

QUIJANO, A. Colonialidade do poder e classificação social. In: SOUSA SANTOS, B. de (Org.). Epistemologias do sul. Coimbra: Almedina, 2009. p. 73-117.

RODRÍGUEZ, S. La defensa de Bolivar. Caracas: Ediciones del Rectorado, 2006.

SOUSA SANTOS, B. de. Renovar a teoria crítica e reinventar a emancipação social. São Paulo: Boitempo, 2007.

SCHULTZ, L. Decolonizing social justice education: from policy knowledge to citizenship action. In: ABDI, A. A. (Ed.). Decolonizing philosophies of education. Roterdam: Sense, 2012. p. 29-42.

WEYH, C. B. Educar pela participação: uma leitura político-pedagógica do Orçamento Participativo Estadual no município de Salvador das Missões/RS. Santo Ângelo: FURI, 2011.

Texto recebido em 14 de abril de 2017. Texto aprovado em 19 de junho de 2017. 